\title{
Lightning and rain dynamic indices as predictors for flash floods events in the Mediterranean
}

\author{
N. Harats ${ }^{1}$, B. Ziv ${ }^{2}$, Y. Yair ${ }^{2}$, V. Kotroni ${ }^{3}$, and U. Dayan ${ }^{1}$ \\ ${ }^{1}$ The Hebrew University of Jerusalem, Jerusalem, Israel \\ ${ }^{2}$ The Open University, Ra' anana, Israel \\ ${ }^{3}$ National Observatory of Athens, Athens, Greece \\ Received: 26 February 2009 - Revised: 9 March 2010 - Accepted: 12 March 2010 - Published: 29 March 2010
}

\begin{abstract}
The FLASH EU funded project aims to observe, analyze and model lightning activity in thunderstorms for use in short term forecasting of flash floods in the Mediterranean region. Two new indices, aimed to assess the potential for heavy precipitation and flash-floods, are proposed and evaluated. The first is a lightning index - the MKI, which is a modified version of the KI-index. The applied index gives more weight to the lower- and mid-level relative humidity. The second is a new rain index, the RDI, which is the integrated product of specific humidity and vertical velocity. With the aim to contribute to the aforementioned objectives, 3 flash flood events, two in Israel and one in Greece are analyzed in the present study, using the 2 proposed indices.

The NCEP/NCAR reanalysis database, of $2.5^{\circ} \times 2.5^{\circ}$ resolution, failed to resolve the meso-scale features of the observed flash flood events. Therefore, the ECWMF database, of $0.5^{\circ} \times 0.5^{\circ}$ resolution, was used for calculating and displaying the two indices. Comparison between the observed rain and lightning and the respective indices for the two pieces of data was performed for the flash flood events. The results show good concordance of both indices with timing and spatial distribution in 2 of them, while in one of them is displaced by more than $50 \mathrm{~km}$. The good agreement in locating the maximum between the MKI and RDI suggests that the proposed indices are good predictors for both intense lightning activity and torrential rain and consequently, for potential flash floods.
\end{abstract}

Correspondence to: N. Harats (haratsnh@zahav.net.il)

\section{Introduction}

Among the FLASH project objectives are to observe, analyze and model lightning activity in thunderstorms for use as a tool for short term forecasting of flash floods in the Mediterranean region. This study aims to develop two indices; one to predict the potential for lightning activity and a second for predicting heavy precipitation generating flash-floods for the Mediterranean region.

The occurrence of torrential rains and thunderstorms and their intensity depends on a combination of factors, such as temperature profiles and implied instability, atmospheric moisture, lower-level convergence etc. In order to estimate the probability and intensity of the rain and lightning activity, various predictors were combined to estimate the necessary conditions for their occurrence (Foster, 1953; Doswell et al., 1996; Doswell, 2001; Brooks et al., 2007; and Ziv et al., 2009). In each experiment, a set of variables was tailored for the specific region, season and phenomena (flash flood, thunderstorm, tornado etc.).

For the eastern Mediterranean, Rosenfeld and Farbstein (1989) derived a prediction scheme for the daily rainfall depths in Israel based on four predictors: the $1000-500 \mathrm{hPa}$ thickness, the product of the $900 \mathrm{hPa}$ wind speed and the precipitable water in the 1000-600 hPa layer, the southerly wind component and the average Relative Humidity (RH) over the 900-600 hPa layer. Ziv et al. (2009) developed a prediction scheme for the lightning rate over central Israel. The predictors were the temperature difference between the sea surface and $500 \mathrm{hPa}$ level and between 850 and $700 \mathrm{hPa}$ levels, the $\mathrm{RH}$ at $850 \mathrm{hPa}$, the $700-500 \mathrm{hPa}$ wind shear, the vertical

Published by Copernicus Publications on behalf of the European Geosciences Union. 
velocity at $700 \mathrm{hPa}$, the $\mathrm{u}$-wind component at $500 \mathrm{hPa}$ and the sea surface temperature. The variables that compose the lightning and rain predictors demonstrate that for thunderstorms, instability is the major factor, whereas for rainfall the moisture supply is the most essential.

Meteorological indices, developed mainly for forecasting severe weather, are combinations of variables, taking into account mainly the instability, based on vertical temperature differences. The most common instability indices used to predict the potential for lightning activity are the CAPE (Convective Available Potential Energy), the LI (Lifted Index) and the Showalter index (e.g., Doswell, 2001). None of them is used in this study, due to their high sensitivity to small differences in the temperature profile (e.g., Ziv et al., 2009), which limit their effectiveness when applied to gridded data used in this study.

Another well known index is the K-Index (KI; Geer, 1996), which combines instability and moisture availability and it is defined as

$\mathrm{KI}=\left(T_{500}-T_{850}\right)+T d_{850}-\left(T_{700}-T d_{700}\right)$,

where $T$ and $T d$ are the dry bulb and dew point temperatures, respectively, and the subscripts refer to the respective pressure level $(\mathrm{hPa})$. The 1 st term reflects the lapse rate throughout the lower- and mid-troposphere (the lapse-rate term), the 2nd represents the lower-level moisture and the 3rd the saturation deficit in the mid-troposphere. When $15<\mathrm{KI}<19$ there is $20 \%$ likelihood for thunderstorms and when it exceeds 30 the probability for thunderstorms is greater than $85 \%$. The KI, when applied to the average upper-level data of Israel for July-August, yielded a value of 21, corresponding to moderate chance for thunderstorms. Actually, the summer in Israel is rainless and thunderstorms are extremely rare (Ziv et al., 2004). The failure of the KI to represent adequately the summer conditions over the study region can be attributed to the permanent seasonal marine inversion (Dayan and Rodnizki, 1999; Dayan et al., 2002; Bitan and Saaroni, 1992). This inversion is normally below the $850 \mathrm{hPa}$ level and it capes the lower-level moisture within the underlying marine air, while the Relative Humidity $(\mathrm{RH})$ above it (including 850 and $700 \mathrm{hPa}$ levels) varies around $30 \%$. This low RH suppresses potential convection in spite of the large temperature difference between 850 and $500 \mathrm{hPa}$ levels, being $\sim 25^{\circ} \mathrm{C}$.

The use of universal indices, as predictors of rain, is less common than for lightning activity. However, the vertically integrated convergence of the moisture flux is often used as an estimate for evaluating rainfall (e.g., Zangvil et al., 2001). Here two indices are adopted; one for lightning activity and another for rain rate. They are applied for the three flash flood events included in the FLASH project database. The indices are presented in Sect. 2, together with the data used. Section 3 compares the spatial distribution of the indices and their sensitivity to the data resolution and presents the results for the selected flash events. Section 4 summarizes the results and their implications for the rain regime of the Mediterranean and for operational forecasting.

\section{Data and methodology}

\subsection{Regional indices for lightning and rain}

\subsubsection{Lightning index - Modified K-index}

In order to adjust the KI to the study region and to circumvent the overestimation of the lightning probability in the summer season there, a modified version, MKI, hereafter is proposed.

$\mathrm{MKI}=\left(T_{500}-T_{850}\right) \times \mathrm{RH}_{850,700}+T d_{850}-\left(T_{700}-T d_{700}\right)$

The MKI is identical to the KI, except for the lapse-rate term, which is multiplied by the average $\mathrm{RH}$ of the 850 and $700 \mathrm{hPa}$ levels, so that multiplication of the lapse rate term by the average $\mathrm{RH}$ of the 850 and $700 \mathrm{hPa}$ levels reflects the modulating effect of the humidity factor under conditional instability. The MKI is smaller than the KI due to the saturation deficit in the lower- and mid-levels. The result is that under dry conditions MKI falls in lower categories than the original KI. When the air is almost saturated, MKI practically equals KI, but when part of the lower- or the mid-troposphere is dry it becomes considerably lower. When applied to the long-term mean July-August temperature and RH in Israel, it yields 0.5 , implying no thunderstorm conditions. The involvement of the RH in the three terms of the RHs of Eq. (2), explicitly in the first and implicitly (through $T d$ ) in the rest, suggests that it could be reduced. Several performed sensitivity examinations have shown that the 2 nd and the 3 rd terms should better remain intact.

\subsubsection{Rain dynamic index}

The Rain Dynamic Index (RDI, hereafter) is the vertically integrated upward moisture flux throughout the troposphere (excluding the planetary boundary layer) according to:

$\mathrm{RDI}=\int_{Z_{(925 \mathrm{hPa})}}^{Z_{(300 \mathrm{hPa})}} w q d z$,

where $w$ is vertical velocity, and $q$ is specific humidity and $z$ is elevation. Since the data are referring to preset pressurelevels, the vertical integration was done with respect to pressure. The RDI comprises the precipitable water and the dynamic conditions necessary to convert it to rain. Derivation of its spatial distribution based on a $\sim 100 \mathrm{~km}$ resolution data reflects synoptic scale forcing, while derivation from data of tens of kilometers resolution resolves meso-scale factors, such as orography, fronts, squall-lines etc., which are more relevant to flash floods. 


\subsection{Data}

The synoptic maps are based on the NCEP/NCAR reanalysis database, of $2.5^{\circ} \times 2.5^{\circ}$ spatial resolution (Kalnay et al., 1996; Kistler et al., 2001), and 6-h intervals. Initially, this data set was used for drawing the distribution of the indices used. Since it failed to resolve the meso-scale features of the observed flash-flood events (Sect. 3.1), the ECMWF database, with $0.5^{\circ} \times 0.5^{\circ}$ resolution (Unisys Corp. 2005), was used for calculating and displaying them. The synoptic maps, including sea level pressure (slp) and $500 \mathrm{hPa}$ geopotential height (gph) and the spatial distribution of MKI and DRI, were derived using GRADS software (Doty, 1988).

The radar imagery for Israel was taken from the Mekorot Shacham (Morin and Gabella, 2007). This radar is situated at Ben-Gurion airport, in central Israel ( $\left.31^{\circ} 59^{\prime} \mathrm{N}, 34^{\circ} 52^{\prime} \mathrm{E}\right)$, and has a good coverage of most of the country and the adjacent Mediterranean Sea. Radar data resolutions are $5 \mathrm{~min}$ in time and $1 \mathrm{~km}$ in space (polar coordinates). The relevant scans are at the three lowest elevation angles, where the first angle is at the range of $0.6-1^{\circ}$, the second at $1.4-1.7^{\circ}$ and the third at $2.3-2.5^{\circ}$. The radar data presented is in the form of uncalibrated rain totals derived from the radar reflectivity and are used to illustrate qualitatively the rain spatial distribution.

The lightning data for Israel are extracted from The

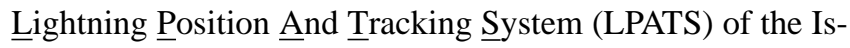
raeli Electrical Corporation. The system is composed of an array of detectors that includes $8 \mathrm{VLF}$ antennas, dispersed over the country. The system is using the time-of-arrival, with time accuracy of $10 \mu$ s, a technique for locating lightning strokes. It also provides real time information on timing and location of every Cloud-to-Ground (CG) lightning flash that occurs in Israel and up to $500 \mathrm{~km}$ from its borders, but intra-cloud lightning discharges are discarded. The LAPTS stations are synchronized by receiving the timing signal from the GPS satellite network. The temporal resolution of the LPATS is about $15 \mathrm{~ms}$ and the position accuracy inside the network is about $500 \mathrm{~m}$ (Katz and Segev, 1995).

The lightning data for Greece are based on the ZEUS system operated by the National Observatory of Athens. ZEUS is a long-range lightning detection network manufactured by Resolution Displays Inc with receivers located at six sites over Europe (in UK, Denmark, Romania, Cyprus, Greece and Portugal). It receives and records the radio noise (sferic) emitted by cloud-to-ground lightning discharges in the verylow-frequency $(7-15 \mathrm{kHz})$. At each receiving station, an identification algorithm is executed that detects sferic candidates and excludes weak signals and noise. It is capable to capture up to 70 sferics (atmospheric pulses associated with electric discharges) per second. The lightning location is retrieved using the arrival time difference triangulation technique. As it concerns the location accuracy of ZEUS, comparison with the LINET lightning detection network (Betz et al., 2004) over Central Europe has shown that the location accuracy of ZEUS is of the order of $4-5 \mathrm{~km}$ over the study area (Lagouvardos et al., 2008). Further details on ZEUS network can be found in Kotroni and Lagouvardos (2008).

\section{Results}

\subsection{Comparison between data of two different spatial resolutions}

In order to choose the optimal data base for the analysis, the maps of the two indices based concurrently on the coarse version (synoptic-scale) of the NCEP/NCAR data and the fine version (meso-scale) of the ECMWF data were derived. The synoptic-scale data (Fig. 1a) does not reveal the main feature, i.e., an elongated band of highly developed and active cloudiness appearing in the satellite image (Fig. 1c). In contrast, the meso-scale resolution data (Fig. 1b) captures it quite well.

\subsection{Case 1: Wadi-Ara event, 1-2 April 2006, Israel}

The case of Wadi-Ara event has been studied and published earlier by Morin et al. (2007). The synoptic background is shown in Fig. 2 by the geopotential heights at 1000 and $500 \mathrm{hPa}$ for 2 April 2006, 00:00 UTC. It reflects the stage at which the torrential rains started. A pronounced upper-level trough has just crossed Israel, and the vorticity advection (not shown) has already become negative, implying that the synoptic background did not support upward motion and rain formation (Holton, 1992). However, the lower level flow implied by the pressure gradient (contours) indicates onshore cyclonic flow associated with the surface cyclone located to the east. This situation was shown by Kahana et al. (2002) as being favorable for flash-floods in the south of Israel due to the combination of moisture transport inland combined with sea-land convergence by the onshore winds and, later on, with forced orographic convection.

The event can be divided into two phases:

- Phase I (1 April 2006, 23:00 UTC-2 April 2006, 01:00 UTC) started with torrential rain along a northwest-southeast orientated line extending from the central coast to the northern of the Dead-Sea (Fig. 1c), shown by the temporally integrated radar reflectivity during the storm peak hours (Fig. 3c). The rain produced all time record intensities, especially for Jerusalem (over $120 \mathrm{~mm}$ in $8 \mathrm{~h}$ ).

- Phase II (2 April 2006, 06:00-12:00 UTC). Shortly after the decay of phase I, a newly rain system developed over northwestern Israel. It produced a 3-h rain record, i.e., total rain depth of more than $200 \mathrm{~mm}$ covered an area of $17 \mathrm{~km}^{2}$ with a maximum value of $263 \mathrm{~mm}$ in WadiAra $\left(\sim 32.5^{\circ} \mathrm{N}, 35^{\circ} \mathrm{E}\right)$, resulting in a record flash-flood (Morin et al., 2007). The respective radar imagery is shown in Fig. 4c. 

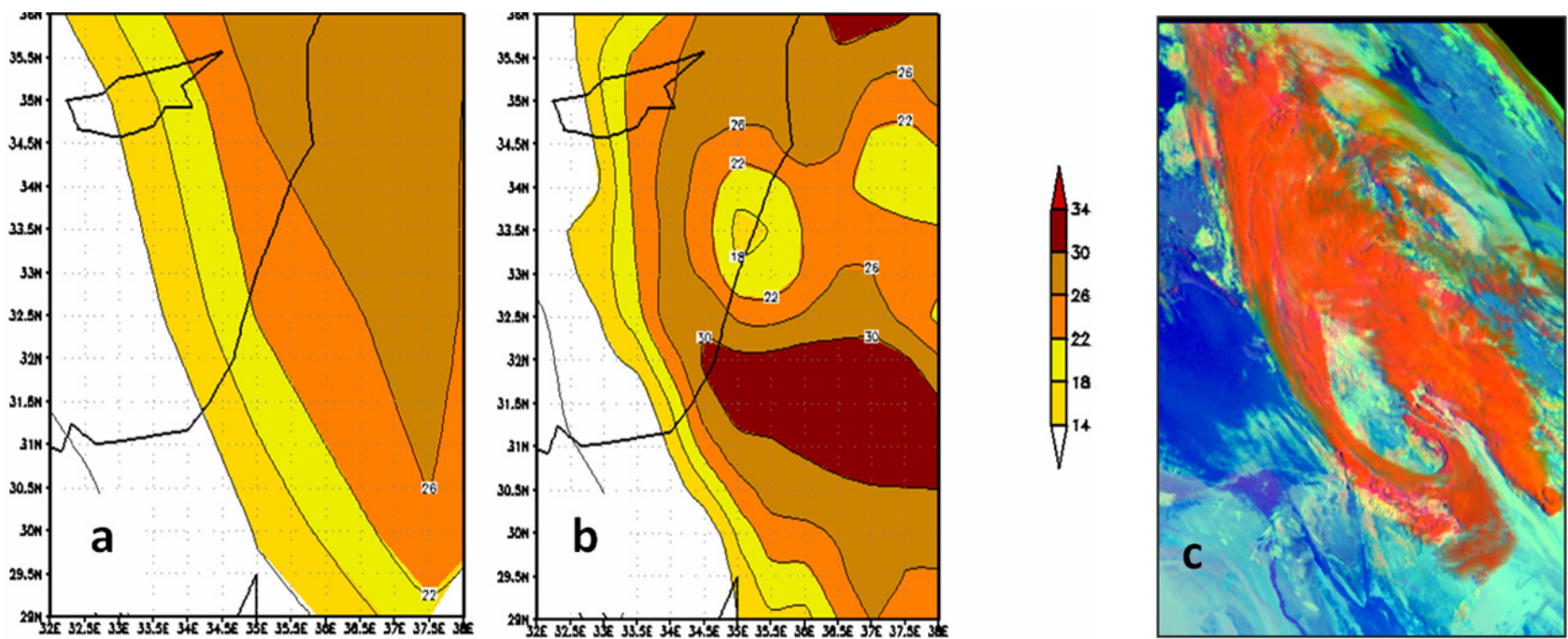

Fig. 1. Spatial distribution of MKI for 2 April 2006, 06:00 UTC, based on (a) NCEP/NCAR with $2.5^{\circ} \times 2.5^{\circ}$ resolution and (b) ECMWF with $0.5^{\circ} \times 0.5^{\circ}$ resolution. (c) Concurrent MSG imagery for the same time, showing the street of clouds (red) that produced the rain.

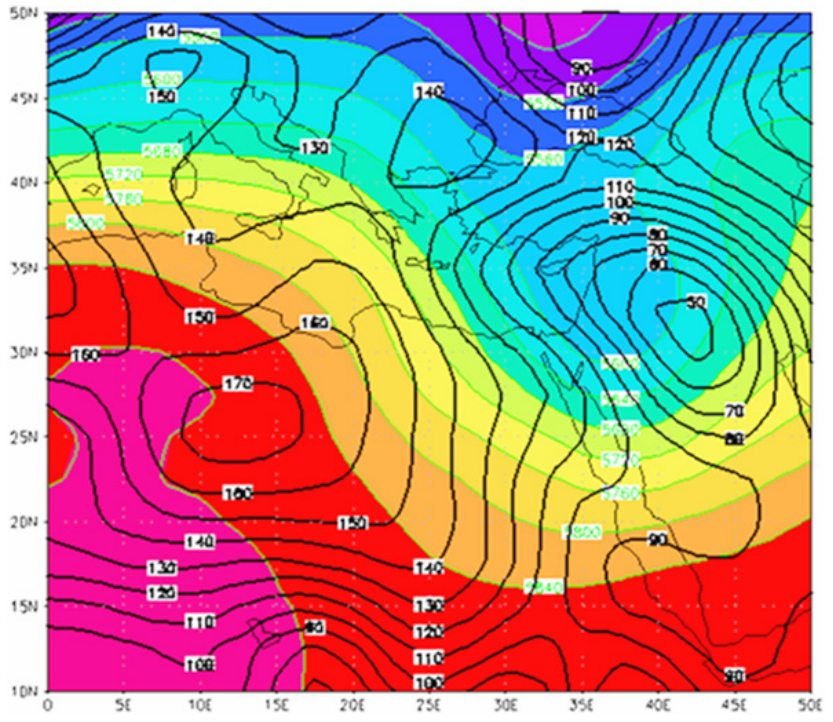

Fig. 2. Geopotential height (gph) at $1000 \mathrm{hPa}$ (contours) and $500 \mathrm{hPa}$ (shading) for 2 April 2006, 00:00 UTC.

The spatial distribution of the two indices for phase I (Fig. 3) portrays results which fully agree with the structure of the main rain cloud system. The picture is less clear in phase II (Fig. 4), presumably due to a time gap of $3 \mathrm{~h}$ between the data and the time of the maximum rain intensity. However, the maximum of both indices falls closer to the core of the rain system of Phase I, which had ended by that time. It is worth noting that while meso-scale data captured well the meso-scale features of the two rain systems, the synoptic-scale data could not resolve them, presumably due to the adverse conditions associated with the upper-level negative vorticity advection over the region. A comparison between the amplitude and spatial distribution of the two indices shows that the locations of their maxima overlap, though minor differences in their structures can be identified.

\subsection{Case 2: Nahal Alexander flood, 8-9 February 2006, Israel}

The second Israeli case presented in this study occurred in the morning of 9 February 2006 in Nahal Alexander, central Is$\operatorname{rael}\left(\sim 32.2^{\circ} \mathrm{N}, 35^{\circ} \mathrm{E}\right)$, as a result of torrential rain over western Samaria toward the end of a rain event that took place on the 8 and 9 February 2006. The region was dominated by a Cyprus low, accompanied by an upper-level trough (not shown). As in case 1 , the rain intensity reached its maximum intensity after the upper-trough has crossed the pertinent region, so that positive vorticity advection has ceased already, and lower-level moisture was transported inland.

The spatial distributions of the two indices, and the corresponding radar composite, are shown in Fig. 5. The maximum values of both indices, as well as the rain intensity, were much lower than in case 1 , as was the rain, though still high enough to explain heavy rain and intense thunderstorms. Nevertheless, the maxima of both indices were found over northern Israel whereas the heaviest rain (and the resulting flash-flood) was observed over $50 \mathrm{~km}$ southeast of it.

\subsection{Case 3: Volos flood, 9-11 October 2006, Greece}

Heavy rainfall and floods were observed on 9 October over eastern Greece, mainly over Volos area $\left(\sim 39.2^{\circ} \mathrm{N}, 23^{\circ} \mathrm{E}\right)$. On the following day, heavy rainfall was recorded over the 

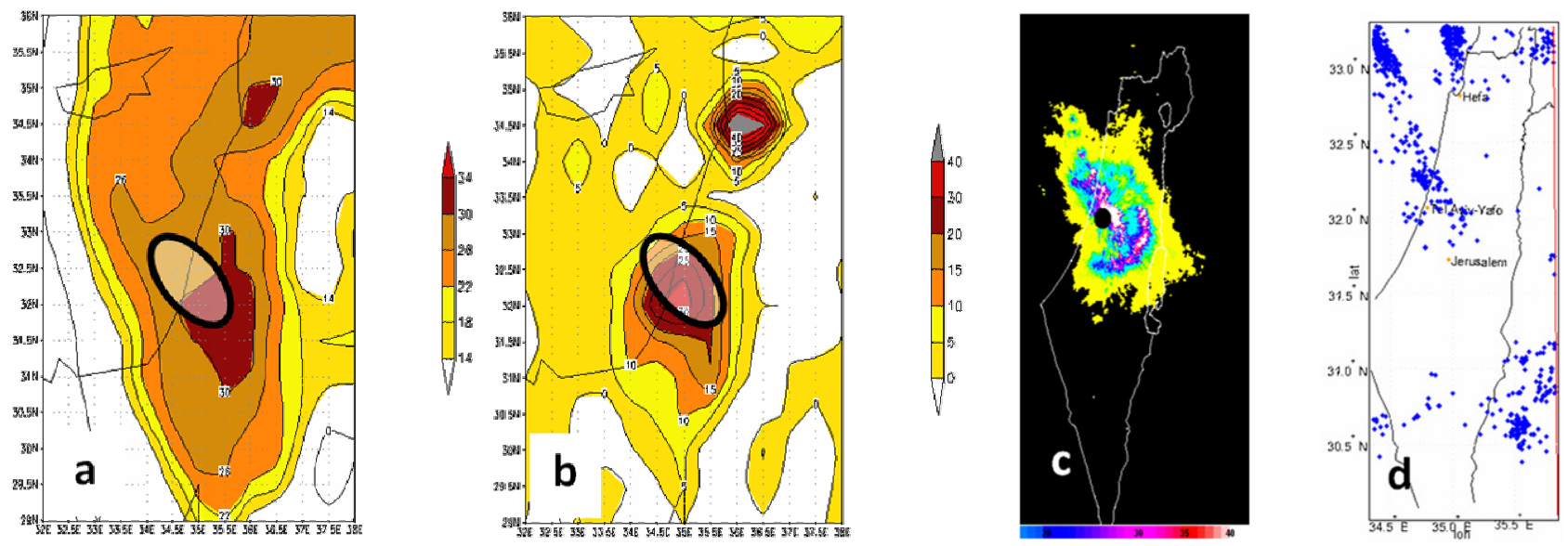

Fig. 3. Spatial distribution of (a) MKI, (b) RDI, both for 2 April, 00:00 UTC, (c) uncalibrated rain totals derived from the radar reflectivity over the period 1 April 2006, 23:00 UTC-2 April 2006, 01:00 UTC and (d) distribution of cloud-to-ground flashes observed by LPATS for 1 April, 00:00 UTC-2 April, 00:00 UTC, representing the 1st phase of the Wadi-Ara event. The bold ellipses in (a) and (b) represent the core of the rain system.
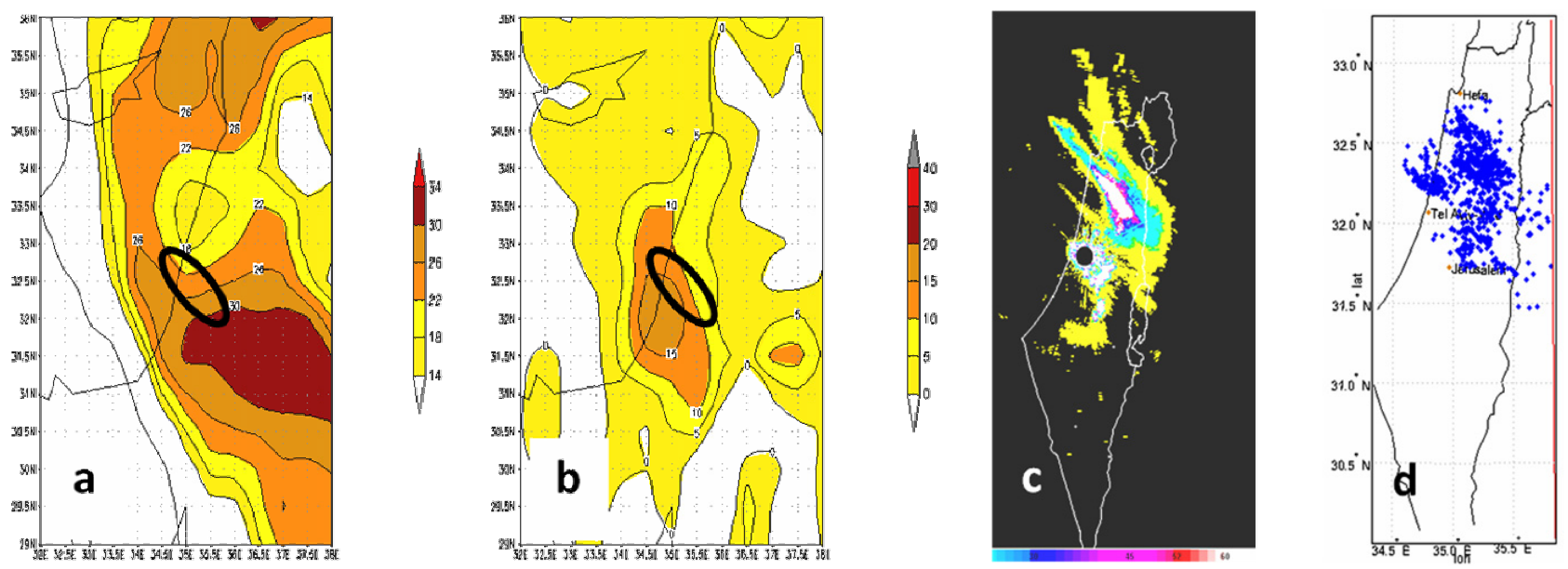

Fig. 4. As in Fig. 3, but for the second phase, 2 April 2006, 06:00 UTC. The radar derived rainfall is integrated over the period 2 April 2006, 06:00-12:00 UTC and the lightning distribution - 2 April, 00:00 UTC-3 April, 00:00 UTC. The bold ellipses in (a) and (b) denote the maximum rain.

Greater Athens Area. A low pressure system of $1008 \mathrm{hPa}$, centered over the Aegean Sea which was associated with a cold front affected the area of Greece on 9 October 2006. The surface system was associated with a $500 \mathrm{hPa}$ cut-off low over the Ionian Sea which was moving very slowly to the southeast without further deepening (Fig. 6). The easterly lower-level flow transported moisture and unstable air from the Aegean Sea toward the eastern parts of Greece. Consequently, heavy and continuous rain, accompanied with thunderstorms, caused flooding in Volos, where $232 \mathrm{~mm}$ rainfall was recorded from 06:00 to 18:00 UTC on 9 October 2006. The convective character of this event is manifested by intense lightning activity recorded on 9 October 2006 (Fig. 7c) over western Peloponnesus (where high MKI values, but low
RDI values were observed) and along the east coast, especially over the area of Volos, where both indices were high.

Since radar imagery was not available, 2-h composite lightning maps based on ZEUS lightning detection network for validation were used. The index maps for the 9 October 2006, along with the corresponding lightning map, are shown in Fig. 7. Comparison between the MKI and RDI distribution (Fig. 7a and b, respectively) show that RDI is more intense and concentrated over the region of Volos, where the maximum of rainfall was recorded. The lightning map for the same day of the storm (Fig. 7c) reflects the intense lightning activity over the target region that correlates spatially well with the RDI maxima, though lightning were observed in other locations. 

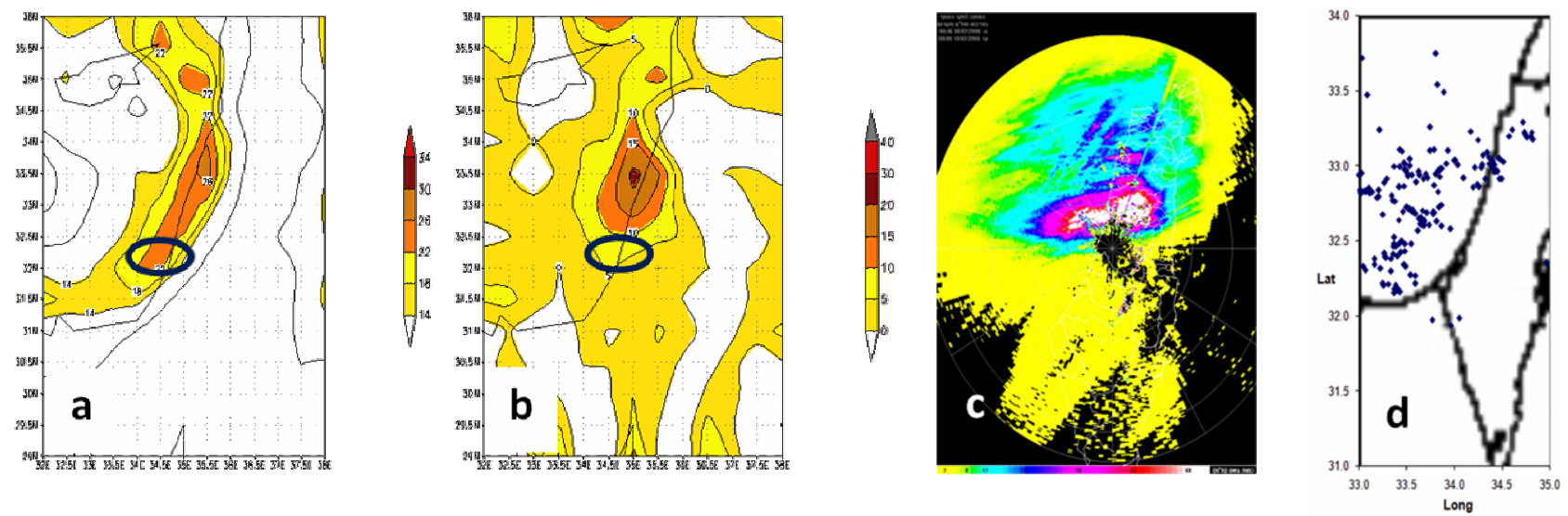

Fig. 5. Same as Fig. 3. The MKI and RDI are for 8 February 2006, 18:00 UTC. The radar derived rainfall and the lightning locations are integrated over 17:20-19:20 UTC. The bold ellipses in (a) and (b) denote the location of the heaviest rain.
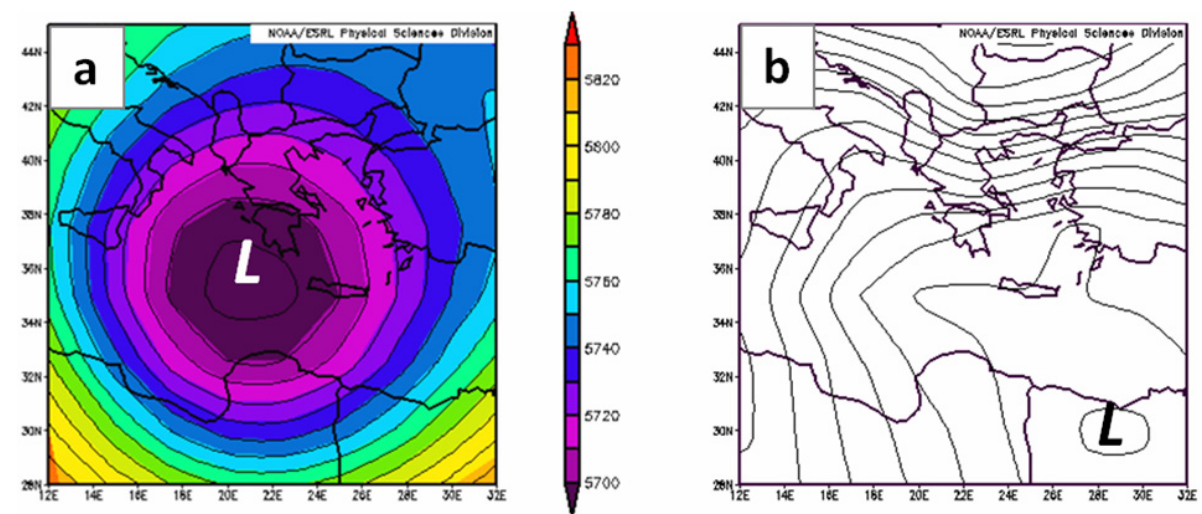

Fig. 6. The synoptic situation, averaged over 9-11 October 2006. (a) $500 \mathrm{hPa}$ and (b) slp.
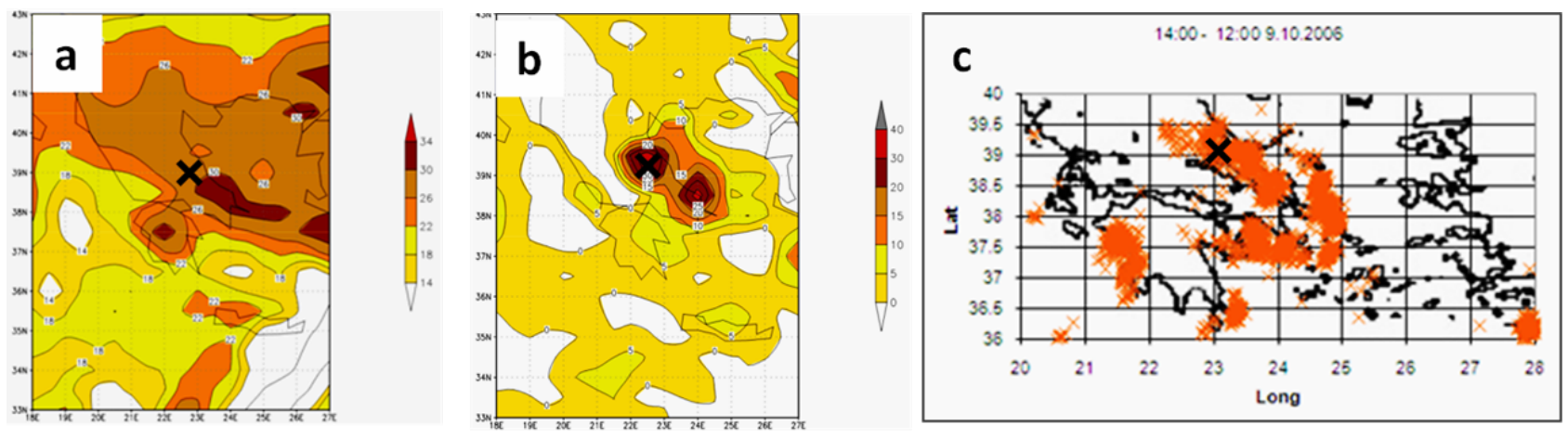

Fig. 7. Spatial distribution of MKI (a) and RDI (b) for 9 October 2006 12:00 UTC and integrated lightning activity for 12:00-14:00 UTC (c). The $\mathrm{X}$ signs for Volos area.

\section{Concluding remarks}

Two new indices, aimed to assess the potential for heavy precipitation and flash-floods, are proposed and evaluated. The first is a lightning index - the MKI, which is a modified version of the KI-index that gives more weight to the lowerand mid-level relative humidity. The second is a new rain index, the RDI, which is the integrated moisture flux within the free troposphere. The present study explores the spatiotemporal distribution of the two indices for three major 
flash-floods that occurred in the Mediterranean region, two in Israel and one in Greece, studied in the framework of the FLASH project.

A preliminary experiment showed that the NCEP-NCAR coarse grid data of $2.5^{\circ} \times 2.5^{\circ}$ resolution fail to resolve the spatial distribution of the storms activity. When derived from $0.5^{\circ} \times 0.5^{\circ}$ resolution data of the ECMWF, the two indices showed high values in the location and timing of the floods themselves. The best accordance was found in the Wadi-Ara (Israel) flood and the weakest - in the Nahal Alexander (Israel) flood, in which the maximum in both indices was over $50 \mathrm{~km}$ apart from the location of the flood. This shift may result from a weakness of the data, which did not resolve a sub-synoptic dynamic evolution at Nahal Alexander area. As for the Volos (Greece) flood the meso-scale spatial distribution matching of the indices and the storm was satisfactory, and coincided with the lightning activity peaks.

At this stage the results are qualitative and further study is on its way in order to define quantitative thresholds for both indices as alarming. However, following the cases studied here tentative values of 25 for the MKI and of 20 for the RDI can be referred as thresholds for potential flash-flood in the Mediterranean. The agreement in the location and timing of the extreme values between the lightning and the rain indices suggests that the factors are correlated. Of course, the lightning factors are not expected to fit perfectly the rain factors, but when torrential rain is concerned, the results indicate that they tend to overlap. This implies that intense lightning activity might serve as good predictor for flash-floods, which supports the underlying hypothesis of the FLASH project.

The synoptic background for the cases analyzed has three features in common: onshore wind, conditional instability and synoptic-scale dynamical conditions which are neutral or even adverse for rain formation. It indicates that the onshore flow of unstable air, when encounters the coasts of the Mediterranean, especially when mountain ridges exist (as is the case in Volos) offer favorable conditions for torrential rains. The major contribution of onshore unstable flow for torrential rains found here is identical to that of $\mathrm{Ziv}$ et al. (2010) for Mediterranean cyclones in general. It may also be hypothesized that the absence of synoptic-scale supportive dynamic does not suppress the development of sub-synoptic features which supply the necessary conditions for torrential rains over small areas, in the order of tens of kilometers.

The results obtained from the three cases analyzed here suggest that the indices developed have the potential to serve as a future forecasting tool when applied to the output of regional forecasting model. The results are still preliminary and MKI and RDI values might still reach values corresponding to flash-flood even for moderate rain, causing a false alarm. An extension of the analysis is planned, as well as the application of the methodology on other parts of the Mediterranean region. Elaboration of the meso-scale features that may be found in other studies of Mediterranean storms and their categorization along these indices might further improve our understanding of the sub-synoptic dynamics characterizing this region. The variations from case to case of the ratio between the lightning and rain indices may yield a tool for calculating the rainfall-lightning relationship.

Acknowledgements. This research was conducted in the framework of the FLASH project for which partial funding was provided, contract number 036852 of the EU 6th Framework Program.

Edited by: S. Michaelides, K. Nicolaides, and A. Orphanou Reviewed by: S. Michaelides, K. Nicolaides, and A. Orphanou

\section{References}

Bitan, A. and Saaroni, H.: The horizontal and vertical extension of the Persian Gulf trough, Int. J. Climatol., 12, 733-747, 1992.

Betz, H. D., Schmidt, K., Oettinger, P., and Wirz, K.: Lightning detection with 3-D discrimination of intracloud and cloud-toground discharges, Geophys. Res. Lett., 31, 108-114, 2004.

Brooks, H. A., Anderson, A. R., Riemann, K., Ebbers, I., and Flachs, H.: Climatological aspects of convective parameters from the NCAR/NCEP reanalysis, Atmos. Res., 83, 294-305, 2007.

Dayan, U., Lifshitz-Goldreich, B., and Pick, K.: Spatial and structural variation of the atmospheric boundary layer during summer in Israel- Profiler and Radiosonde measurements, J. Appl. Meteorol., 41, 447-457, 2002.

Dayan, U. and Rodnizki, J.: The temporal behavior of the atmospheric boundary layer in Israel, J. Appl. Meteorol., 38, 830-836, 1999.

Doswell, C. A., Brooks, H. E., and Maddox, R. A.: Flash flood forecasting: An ingredients-based methodology, Weather Forecast., 11, 560-581, 1996.

Doswell, C. A.: Severe convective storms, Am. Meteorol. Soc., 561 pp., 2001.

Doty, B. E.: Grid analysis and display system (GrADS), Center for Ocean-Land-Atmosphere Interactions, Institute for Global Environment and Society, Calverton, MD, 1988.

Foster, D. S.: The severe weather forecasting program at Kansas City, 1 March to 31 August 1953, 16 pp., 1953.

Geer, I. W.: Glossary of Weather and Climate, Am. Meteorol. Soc., 131, 1996.

Holton, J. R.: An introduction to dynamic meteorology, 3rd edition, NY: Academic Press, 511 pp., 1992.

Kahana, R., Ziv, B., Enzel, Y., and Dayan, U.: Synoptic climatology of major floods In the Negev Desert, Israel, Int. J. Climatol., 22, 867-882, 2002.

Kalnay, E., Kanamitsu, M., Kistler, R., Collins, W., Deaven, D., Gandin, L., Iredell, M., Saha, S., White, G., Woollen, J., Zhu, Y., Chelliah, M., Ebisuzaki, W., Higgins, W., Janowiak, J., Mo, K. C., Ropelewski, C., Wang, J., Leetmaa, A., Reynolds, R., Jenne, R., and Joseph, D: The NCEP/NCAR 40-years reanalysis project, B. Am. Meteorol. Soc., 77, 437-472, 1996.

Katz, E. and Segev, A.: The Lightning Position and Tracking System (LPATS) in Israel: first results, in: The 18th Convention of Electrical and Electronics Engineers in Israel, 3.1.5/5 pp., 78 March, 1995. 
Kistler, R., Kalnay, E., Collins, W., Saha, S., White, G., Woollen, J., Chelliah, M., Ebisuzaki, W., Kanamitsu, M., Kousky, V., Van Den Dool, H., Jenne, R., and Fiorino, M: The NCEP-NCAR 50year Reanalysis: Monthly means CD-ROM and documentation, B. Am. Meteorol. Soc., 82, 247-267, 2001.

Kotroni, V. and Lagouvardos, K.: Lightning occurrence in relation with elevation, terrain slope and vegetation cover over the Mediterranean, J. Geophys. Res., 113, D21118, doi:10.1029/2008JD010605, 2008.

Lagouvardos, K., Kotroni, V., Betz, H., and Schmidt, K.: Assessment of the ZEUS lightning detection network over Europe by comparison with lightning data from LINET, 10th EGU Plinius Conference on Mediterranean Storms, Nicosia, Cyprus, 2224 September, 2008.

Morin, E. and Gabella, M.: Radar-based quantitative precipitation estimation over Mediterranean and dry climate regimes, J. Geophys. Res., 112, D20108, doi:10.1029/2006JD008206, 2007.

Morin, E., Harats, N., Jacoby, Y., Arbel, S., Getker, M., Arazi, A., Grodek, T., Ziv, B., and Dayan, U.: Studying the extremes: hydrometeorological investigation of a flood-causing rainstorm over Israel, Adv. Geosci., 12, 107-114, 2007,

http://www.adv-geosci.net/12/107/2007/.
Rosenfeld, D. and Farbstein, H.: Possible influence of desert dust on seedability of clouds in Israel, J. Appl. Meteorol., 31, 722-731, 1992.

Zangvil, A., Portis, D. H., and Lamb, P. J.: Investigation of the large-scale atmospheric moisture field over the mid-western United States in relation to summer precipitation, Part I: Relationships between moisture budget components on different timescales, J. Climate, 14, 582-597, 2001.

Ziv, B., Saaroni, H., and Alpert, P.: The factors governing the summer regime of the eastern Mediterranean, Int. J. Climatol., 24, 1859-1871, 2004.

Ziv, B., Saaroni, H., Yair, Y., Ganot, M., Baharad, A., and Isaschari, D.: Atmospheric factors governing winter thunderstorms in the coastal region of the Eastern Mediterranean, Theor. Appl. Climatol., 95, 301-310, 2009.

Ziv, B., Saaroni, H., Romem, M., Heifetz, E., Harnik, N., and Baharad, A.: Analysis of Conveyor Belts in Winter Mediterranean Cyclones, Theor. Appl. Climatol., 99(3), 441-455, 2010. 